\title{
CXCL1 stimulates migration and invasion in ER-negative breast cancer cells via activation of the ERK/MMP2/9 signaling axis
}

\author{
CHENGCHENG YANG ${ }^{1-3^{*}}$, HAOCHEN YU $^{1 *}$, RUI CHEN $^{1}$, KAI TAO $^{4}$, LEI JIAN $^{1}$, \\ MEIXI PENG ${ }^{2}$, XIAOTIAN LI ${ }^{1}$, MANRAN LIU ${ }^{2}$ and SHENGCHUN LIU ${ }^{1}$ \\ ${ }^{1}$ Department of Endocrine and Breast Surgery, The First Affiliated Hospital of Chongqing Medical University; \\ ${ }^{2}$ Key Laboratory of Laboratory Medical Diagnostics, Chinese Ministry of Education, Chongqing Medical University, \\ Chongqing 400016; ${ }^{3}$ Department of Breast Surgery, The People's Hospital of Deyang, Deyang, Sichuan 618000; \\ ${ }^{4}$ Department of the Second of Gynecology Oncology, Shanxi Provincial Tumor Hospital, \\ The Affiliated Hospital of Medical College of Xi'an Jiaotong University, Xi'an, Shanxi 710061, P.R. China
}

Received January 11, 2019; Accepted July 1, 2019

DOI: 10.3892/ijo.2019.4840

\begin{abstract}
Chemokine (C-X-C motif) ligand 1 (CXCL1), a member of the CXC chemokine family, has been reported to be a critical factor in inflammatory diseases and tumor progression; however, its functions and molecular mechanisms in estrogen receptor $\alpha(\mathrm{ER})$-negative breast cancer (BC) remain largely unknown. The present study demonstrated that CXCL1 was upregulated in ER-negative BC tissues and cell lines compared with ER-positive tissues and cell lines. Treatment with recombinant human CXCL1 protein promoted ER-negative $\mathrm{BC}$ cell migration and invasion in a dose-dependent manner, and stimulated the activation of phosphorylated (p)- extracellular signal-regulated kinase (ERK)1/2, but not p-STAT3 or p-AKT. Conversely, knockdown of CXCL1 in BC cells attenuated these effects. Additionally, CXCL1 increased the expression of matrix metalloproteinase (MMP)2/9 via the ERK1/2 pathway. Inhibition of MEK1/2 by its antagonist U0126 reversed the effects of CXCL1 on MMP2/9 expression. Furthermore, immunohistochemical analysis revealed a strong positive association between CXCL1 and p-ERK1/2 expression levels in BC tissues. In conclusion, the present study demonstrated that CXCL1 is highly expressed in ER-negative $\mathrm{BC}$, and stimulates $\mathrm{BC}$ cell migration and invasion via the
\end{abstract}

Correspondence to: Professor Shengchun Liu, Department of Endocrine and Breast Surgery, The First Affiliated Hospital of Chongqing Medical University, 1 You-Yi Road, Yuzhong, Chongqing 400016, P.R. China

E-mail: liushengchun1968@163.com

Professor Manran Liu, Key Laboratory of Laboratory Medical Diagnostics, Chinese Ministry of Education, Chongqing Medical University, 1 You-Yi Road, Yuzhong, Chongqing 400016, P.R. China E-mail: manranliu@cqmu.edu.cn

${ }^{*}$ Contributed equally

Key words: chemokine (C-X-C motif) ligand 1, ERK1/2 signaling, estrogen receptor-negative breast cancer, tumor invasion
ERK/MMP2/9 pathway. Therefore, CXCL1 may serve as a potential therapeutic target in ER-negative BC.

\section{Introduction}

Breast cancer (BC) is the most common type of malignant tumor in females and is composed of numerous subtypes with a high heterogeneity (1). In total, $60-70 \%$ of human BC cases are associated with an overexpression of estrogen receptor $\alpha$ (ER) and are sensitive to endocrine therapy $(2,3)$. Compared with ER-positive patients, ER-negative patients exhibit a more aggressive phenotype, metastasis and a poor prognosis $(4,5)$. There is a marked difference in the gene expression profiles of ER-negative and ER-positive BC (6-8). However, few specific factors associated with ER-negative BC have been identified. Therefore, it remains a major challenge to identify novel molecular targets for the treatment of ER-negative BC, which may prevent progression.

Chemokine (C-X-C motif) ligand 1 (CXCL1) belongs to the CXC chemokine family, a family composed of small peptides, and was originally identified in melanoma tumors $(9,10)$. CXCL1 binds specifically to the $\mathrm{G}$ protein-coupled receptor chemokine (C-X-C motif) receptor 2 (CXCR2), which is a member of the CXC chemokine receptor family (11). Aberrant expression of CXCL1 has been identified in numerous types of malignancy, and has been associated with oncogenesis, metastasis, angiogenesis and chemoresistance (12-14). Acharyya et al (12) reported that CXCL1, as an important molecule, was involved in the endothelial-cancer-marrow signaling network, and linked tumor metastasis and drug resistance. Wang et al (15) also identified that CXCL1 secreted by lymphatic endothelial cells promoted gastric cancer progression via integrin subunit $\beta 1$ /focal adhesion kinase/AKT signaling. These findings indicated that CXCL1 may act as a pro-tumorigenic molecule in a paracrine manner following its secretion by non-tumor cells. Previously, the overexpression of CXCL1 in tumor cells has been reported in various types of cancer, including prostate cancer, hepatocellular carcinoma and gastric carcinoma (16-18). Previous studies have also demonstrated that CXCL1 is upregulated in the plasma and 
stroma of patients with BC $(19,20)$; however, whether there is a difference in CXCL1 expression depending on the expression levels of $\mathrm{ER}$ in $\mathrm{BC}$ remains unclear and requires further investigation.

The present study analyzed CXCL1 expression in breast tumor tissues by reverse transcription-quantitative PCR (RT-qPCR) and immunohistochemistry (IHC), which revealed that CXCL1 was highly expressed in ER-negative BC tissues compared with ER-positive BC tissues. In addition, the present study further investigated the expression of CXCL1 in BC cell lines. Furthermore, it was revealed that CXCL1 secreted by tumor cells may promote ER-negative BC cell metastasis via the ERK/matrix metalloproteinase (MMP)2/9 signaling pathway in a CXCR2-dependent manner. IHC assays also suggested that phosphorylated (p)-ERK1/2 was positively associated with CXCL1 protein in BC tissues.

\section{Materials and methods}

Cell culture and reagents. The ER-negative $\mathrm{BC}$ cell lines BT-549, MDA-MB-231 MDA-MB-468, and HS578t, and the ER-positive BC cell lines T47D, MCF-7 and ZR-75-1 were purchased from the American Type Culture Collection and maintained in RPMI-1640 medium (Gibco; Thermo Fisher Scientific, Inc.) or Dulbecco's modified Eagle's medium/F12 with $10 \%$ fetal bovine serum (both from Gibco; Thermo Fisher Scientific, Inc.), $100 \mu \mathrm{g} / \mathrm{ml}$ streptomycin and $100 \mathrm{U} / \mathrm{ml}$ penicillin (Invitrogen; Thermo Fisher Scientific, Inc.) at $37^{\circ} \mathrm{C}$ in a $5 \% \mathrm{CO}_{2}$ standard humidified incubator. For time- and dose-dependence experiments, MDA-MB-231 and BT-549 $\mathrm{BC}$ cells were treated with recombinant human (rh)CXCL1 at concentrations of $0,0.1,1$ or $10 \mathrm{ng} / \mathrm{ml}$ for $1 \mathrm{~h}$ at $37^{\circ} \mathrm{C}$, and treated with $1 \mathrm{ng} / \mathrm{ml} \mathrm{rhCXCL1}$ for $0,10,30,60 \mathrm{~min}$ at $37^{\circ} \mathrm{C}$ in a $5 \% \mathrm{CO}_{2}$ standard humidified incubator. MDA-MB-231 and BT-549 BC cells were treated the combinations of treatments $(1 \mathrm{ng} / \mathrm{ml}$ $\mathrm{rhCXCL1}+200 \mathrm{nM}$ SB225002, $1 \mathrm{ng} / \mathrm{ml} \mathrm{rhCXCL} 1+5 \mu \mathrm{M}$ $\mathrm{U} 0126,1 \mathrm{ng} / \mathrm{ml} \mathrm{rhCXCL} 1+200 \mathrm{nM} \mathrm{SB} 225002+5 \mu \mathrm{M}$ $\mathrm{U} 0126)$ at $37^{\circ} \mathrm{C}$ in a $5 \% \mathrm{CO}_{2}$ standard humidified incubator. rhCXCL1 (cat. no. 275-GR) was obtained from R\&D Systems, Inc. The CXCR2 inhibitor SB225002 (cat. no. S7651) and the MEK1/2 inhibitor U0126 (cat. no. S1102) were purchased from Selleck Chemicals.

Cell migration and invasion assays. For the cell migration assay, $3 \times 10^{5}$ MDA-MB-231 or BT-549 cells in $200 \mu 1$ serum-free medium were seeded into the upper chamber of a Transwell plate (EMD Millipore), and complete medium with or without various concentrations $(0.1,1.0$ and $10 \mathrm{ng} / \mathrm{ml})$ of CXCL1, $\mathrm{U} 0126(5 \mu \mathrm{M})$ and SB225002 $(200 \mathrm{nM})$ was added to the lower compartment. Wells without CXCL1 served as controls. The cells were incubated for $12 \mathrm{~h}$ at $37^{\circ} \mathrm{C}$, then the Transwell inserted were removed and washed, and cells were fixed with $4 \%$ paraformaldehyde for $15 \mathrm{~min}$ at room temperature and stained with $0.5 \%$ crystal violet for $5 \mathrm{~min}$ at room temperature. The numbers of migratory cells in five randomly selected fields were counted under an inverted light microscope (magnification, x200; TE2000-U; Nikon Corporation).

For the cell invasion assay the upper chamber was coated with Matrigel (EMD Millipore) as described previously (21). The remaining steps were the same as the migration assay. After
$24 \mathrm{~h}$ of incubation at $37^{\circ} \mathrm{C}$, the numbers of invaded cells in five randomly selected fields were counted (magnification, x200).

Knockdown of CXCL1. For knockdown of CXCL1 in MDA-MB-231 and BT-549 cells, lentiviral expression vectors containing CXCL1 short hairpin RNA (shRNA) or control shRNA were obtained from Shanghai GenePharma Co., Ltd. The sequence of CXCL1 shRNA was 5'-GCACATCTGTTTT GTAACT-3', and the control shRNA sequence was 5'-TTC TCCGAACGTGTCACGT-3'. Cells at a density of $30-50 \%$ in 6-well plates were transfected with sh-CXCL1 or sh-Ctrl lentivirus $\left(1 \times 10^{8} \mathrm{TU} / \mathrm{ml}\right)$. After $8-12 \mathrm{~h}$ of incubation, the medium was replaced with complete medium containing FBS and puromycin. Further experiments were performed after $\geq 2$ weeks.

$R N A$ isolation and RT-qPCR. Total RNA was extracted from human tissue specimens and cells using TRIzol (Invitrogen; Thermo Fisher Scientific, Inc.), according to the manufacturer's protocol. RNA was reverse transcribed using the PrimeScript RT Master Mix kit (Takara Biotechnology, Co., Ltd.), according to the manufacturer's protocol. RT was conducted as follows: $15 \mathrm{~min}$ at $37^{\circ} \mathrm{C}$ for three times, followed by inactivation at $85^{\circ} \mathrm{C}$ for 5 sec. qPCR was performed with SYBR Pre-mix Ex $\mathrm{Taq}^{\mathrm{TM}}$ II (Takara Biotechnology, Co., Ltd.) according to the manufacturer's protocol. qPCR was conducted as follows: $2 \mathrm{~min}$ at $95^{\circ} \mathrm{C}$, followed by 39 cycles at $95^{\circ} \mathrm{C}$ for $30 \mathrm{sec}, 30 \mathrm{sec}$ at $58^{\circ} \mathrm{C}$ and $20 \mathrm{sec}$ at $72^{\circ} \mathrm{C}$. The sequences of the primers for CXCL1, GAPDH, MMP2 and MMP9 are listed in Table I. Relative gene expression was normalized to GAPDH and calculated using the $2^{-\Delta \Delta C q}$ method (22). The experiment was independently repeated in triplicate.

Western blot analysis. Total proteins were extracted using RIPA lysis buffer with PMSF (both from Beyotime Institute of Biotechnology). Protein concentrations were assessed using a BCA Protein Assay kit (Beyotime Institute of Biotechnology). A total of $40 \mu \mathrm{g}$ protein was separated by $8-10 \%$ SDS-PAGE and transferred onto PVDF membranes. After blocking with $5 \%$ skim milk for $1 \mathrm{~h}$ at room temperature, the membranes were incubated at $4^{\circ} \mathrm{C}$ overnight with the following primary antibodies: p-ERK1/2 (1:1,000; cat. no. AF1891; Beyotime Institute of Biotechnology); ERK1/2 (1:5,000; cat. no. ab184699); p-AKT (1:1,000; cat. no. ab38449) (both from Abcam); AKT (1:1,000; cat. no. 9272S); STAT3 (1:1,000; cat. no. 12640S) (both from Cell Signaling Technology, Inc.); p-STAT3 (1:5,000; cat. no. ab76315); p-ribosomal S6 kinase P90 (p-RSK1P90; 1:5,000; cat. no. ab32203); RSK1P90 (1:5,000; cat. no. ab32114); MMP9 (1:5,000; cat. no. ab76003); MMP2 (1:2,000; cat. no. ab92536) (all from Abcam); and GAPDH (1:1,000; cat. no. 5174S; Cell Signaling Technology, Inc.). Subsequently, appropriate horseradish peroxidase (HRP)-conjugated secondary antibodies (1:1,000; cat. nos. 7074S and 7076S; Cell Signaling Technology, Inc.) were applied for $1 \mathrm{~h}$ at $37^{\circ} \mathrm{C}$. The immunoreactive bands were detected using an enhanced chemiluminescence reagent (EMD Millipore).

Immunofluorescence (IF). An IF assay was performed as described previously (21). Cells were grown on glass coverslips for $24 \mathrm{~h}$, fixed with $4 \%$ paraformaldehyde for $20 \mathrm{~min}$ at room temperature, permeabilized with $0.1 \%$ Triton $\mathrm{X}-100$ for 
Table I. Primers used for reverse transcription-quantitative PCR analysis.

\begin{tabular}{lll}
\hline Gene & \multicolumn{1}{c}{ Forward } & Reverse \\
\hline CXCL1 & 5'-TCCTGCATCCCCCATAGTTA-3' & 5'-CTTCAGGAACAGCCACCAGT-3' \\
GAPDH & 5'-CTCTGCTCCTCCTGTTCGAC-3' & 5'-GCGCCCAATACGACCAAATC-3' \\
MMP2 & 5'-TTGATGGCATCGCTCAGATC-3' & 5'-TGTCACGTGGCGTCACAGT-3' \\
MMP9 & 5'-GGTTCAGGCGAGGACCATAGAG-3' & 5'-TTTGACAGCGACAAGAAGTGG-3'
\end{tabular}

CXCL1, chemokine (C X C motif) ligand 1; MMP, matrix metalloproteinase.

15 min and then blocked with $10 \%$ normal goat serum (cat. no. C0265; Beyotime Institute of Biotechnology) for $30 \mathrm{~min}$ at room temperature. The cells were incubated overnight at $4^{\circ} \mathrm{C}$ with specific primary antibodies against CXCL1 (1:200; cat. no. ab89318; Abcam). After washing three times with PBS, the cells were stained with FITC-conjugated goat anti-rabbit secondary antibody (1:200; cat. no. TA130022; OriGene Technologies, Inc.) for $1 \mathrm{~h}$ at room temperature. The cell nucleus was stained with DAPI for $5 \mathrm{~min}$ at room temperature. IF images were obtained with a Nikon Eclipse 80i microscope (magnification, x400; Nikon Corporation)

Patients and samples. A total of 87 paired human breast tissue specimens, including tumor and adjacent non-tumor tissue, were obtained from the First Affiliated Hospital of Chongqing Medical University. All patients (20-72 years old) underwent surgery for BC at the First Affiliated Hospital of Chongqing Medical University between November 2015 and June 2016. All patients had their primary site in the breast and were diagnosed specifically with $\mathrm{BC}$ for the first time by the Clinical Diagnostic Pathology Center of Chongqing Medical University. The ER status of the patient was determined according to the results of immunohistochemistry by the Clinical Diagnostic Pathology Center of Chongqing Medical University. The study was approved by the Ethics Committee of Chongqing Medical University. Written informed consent was obtained from all patients.

IHC. IHC staining was performed as described previously (21). The human tissues were fixed with $4 \%$ formaldehyde buffer for 12-24 h at room temperature. Deparaffinized specimens were then sectioned (4- $\mu \mathrm{m}$ thick slices). The slices were autoclaved at $115^{\circ} \mathrm{C}$ for $5 \mathrm{~min}$ for antigen retrieval in citric acid buffer ( $\mathrm{pH}$ 6.0), quenched for endogenous peroxidase activity with $0.3 \% \mathrm{H}_{2} \mathrm{O}_{2}$ solution for $10-15 \mathrm{~min}$, blocked for non-specific binding with $10 \%$ normal goat serum for 10-15 min at room temperature, and incubated with specific rabbit primary antibodies against CXCL1 (1:400; cat. no. ab89318; Abcam) and p-ERK1/2 (1:200; cat. no. AF1891; Abcam) overnight at $4^{\circ} \mathrm{C}$. Subsequently, the sections were treated with HRP-conjugated goat anti-rabbit IgG secondary antibody (1:200; cat. no. TA140003; OriGene Technologies, Inc.) for $30 \mathrm{~min}$ at room temperature. After staining with diaminobenzidine (OriGene Technologies, Inc.) and hematoxylin for $5 \mathrm{sec}$ at room temperature, images were captured using a Nikon Eclipse 80 i microscope (magnification, x200; Nikon Corporation). CXCL1 and p-ERK1/2 staining intensities (I) were scored as:
$0,1,2,3$. The percentage of the stained area (A) was scored as: $1(0-25 \%), 2(26-50 \%), 3(51-75 \%)$ and 4 (76-100\%). The sum of the intensity and percentage scores ( + A) was used as the final IHC score. Expression was analyzed using Image-Pro Plus 6.0 software (Media Cybernetics, Inc.).

Enzyme-linked immunosorbent assay (ELISA). BC cells were seeded in a 6 -well cultured plate at a density of $5 \times 10^{5}$ cells. Following culture for $12 \mathrm{~h}$, the suspension was replaced with $1 \mathrm{ml}$ serum-free media. After the cells were starved for $24 \mathrm{~h}$, the supernatants were harvested and centrifuged in $1,000 \mathrm{x} \mathrm{g}$ for $10 \mathrm{~min}$ at room temperature. Concentrations of secreted CXCL1 in the supernatants were determined using a human CXCL1/GRO $\alpha$ Quantikine ELISA kit (cat. no. DGR00B; $\mathrm{R} \& \mathrm{D}$ Systems, Inc.) according to the manufacturer's protocol.

Oncomine database analysis. Oncomine, a cancer microarray database, was screened for breast cancer datasets where ER status was determined (wwww.oncomine.org) (23). A total of 4 independent microarrays, including Bittner (GSE2109), The Cancer Genome Atlas database, Sorlie (24) and Desmedt (25) were obtained from the Oncomine database. CXCL1 expression was analyzed in ER-negative and ER-positive BC with the $\mathrm{R}$ (version 3.5.1) package ggstatspot (indrajeetpatil.github.io/ggstatsplot).

Statistical analysis. SPSS 20.0 software (IBM Corp.) was used for all statistical analysis. Data of three independent experiments are presented as the mean \pm standard deviation. One-way ANOVA followed by Dunnett's multiple comparisons tests was used to evaluate the significant differences among multiple groups. Fisher's exact test was used to evaluate associations between the detected protein expression levels of CXCL1 and p-ERK1/2. $\mathrm{P}<0.05$ was considered to indicate a statistically significant difference.

\section{Results}

Increased expression of CXCL1 $\mathrm{mRNA}$ in ER-negative $B C$ tissues. To analyze the expression of CXCL1 in human BC tissues, the relative mRNA expression levels of CXCL1 in all 87 samples were examined. The clinical parameters of the patients with BC are presented in Table II. The CXCL1 mRNA levels in ER-negative BC tissues $(n=55)$ were significantly upregulated compared with the ER-positive BC tissues $(n=32$; Fig. 1A). In addition, four independent microarrays obtained from the Oncomine public database were analyzed. The mRNA 
A

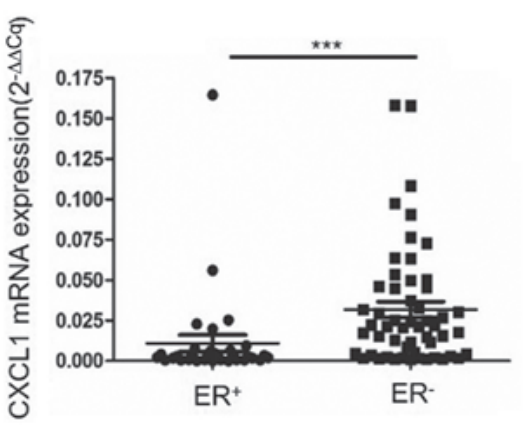

$\mathrm{B}$

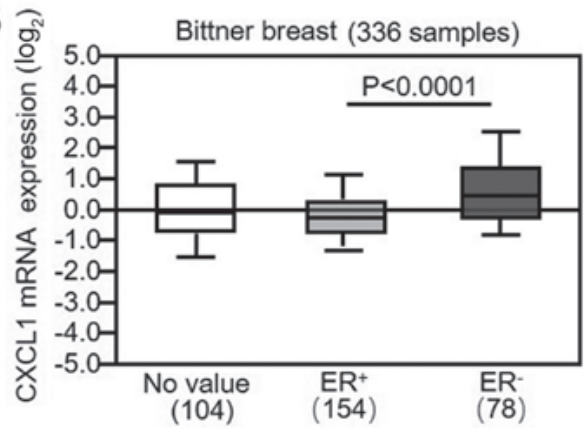

$\mathrm{C}$ 옹

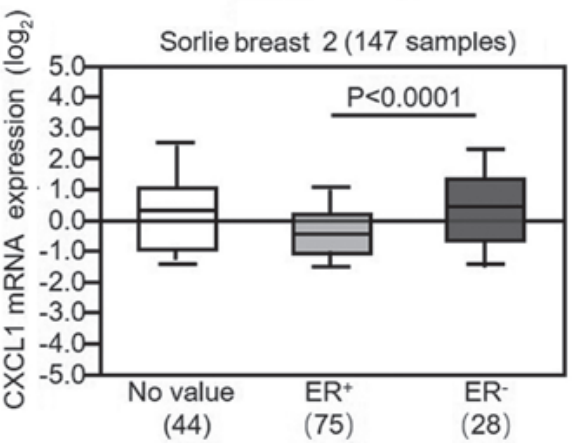

(44)

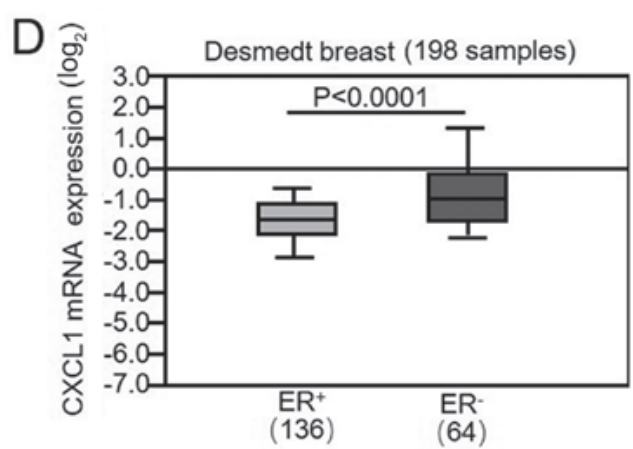

E

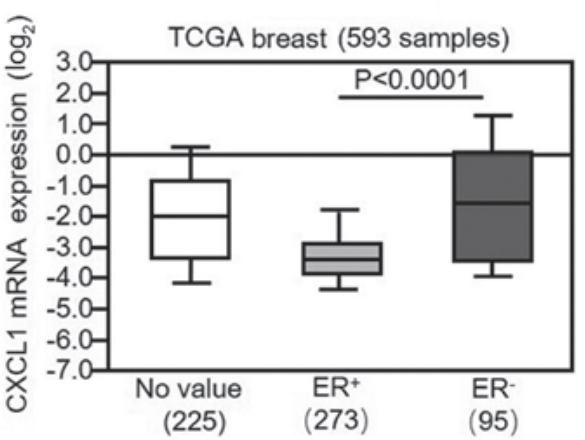

Figure 1. Increased CXCL1 mRNA expression in ER-negative BC. (A) Relative mRNA expression levels of CXCL1 were measured in BC tissues via reverse transcription-quantitative PCR analysis. $n=87$. ${ }^{* * * *} \mathrm{P}<0.0001$. (B-E) Relative mRNA expression levels of CXCL1 in ER-negative BC cases compared with ER-positive BC cases derived from the Bittner, Sorlie, Desmedt and The Cancer Genome Atlas datasets in the Oncomine public database. BC, breast cancer; CXCL1, chemokine (C-X-C motif) ligand 1; ER, estrogen receptor.
Table II. Clinicopathological characteristics of breast tumors $(\mathrm{n}=87)$.

Characteristics

Number $(\%)$

Age (years)

$<45$

$30(34.5)$

$\geq 45$

57 (65.5)

Lymph node metastasis

Negative

Positive

Tumor size $(\mathrm{cm})$

$<2$

$20(23.0)$

$\geq 2$ to $<5$

$\geq 5$

Histological grade (54)

I

II

III

Unknown

11 (12.6)

ER status

Negative

Positive

PR status

Negative

Positive

32 (36.8)

HER2 status

Negative

$47(54.0)$

Positive

38 (43.7)

Unknown

$2(2.3)$

Ki 67 (\%)

$<14$

26 (29.9)

$\geq 14$

$61(70.1)$

p53

Negative

Positive

64 (73.6)

Chemotherapy

Yes

No

67 (77.0)

ER, estrogen receptor; HER2, human epidermal growth factor receptor 2; PR, progesterone receptor.

expression levels of CXCL1 were significantly upregulated in the ER-negative $\mathrm{BC}$ cases compared with the ER-positive $\mathrm{BC}$ cases in the Bittner, Sorlie and Desmedt breast databases and The Cancer Genome Atlas database (Fig. 1B-E). In summary, these results suggest that there is high expression of CXCL1 mRNA in ER-negative breast tumors.

CXCL1 is upregulated in ER-negative BC cells. To further verify the association between CXCL1 expression and ER-negative BC, four ER-negative BC cell lines (BT-549, MDA-MB-231, MDA-MB-468 and HS578t) and three 

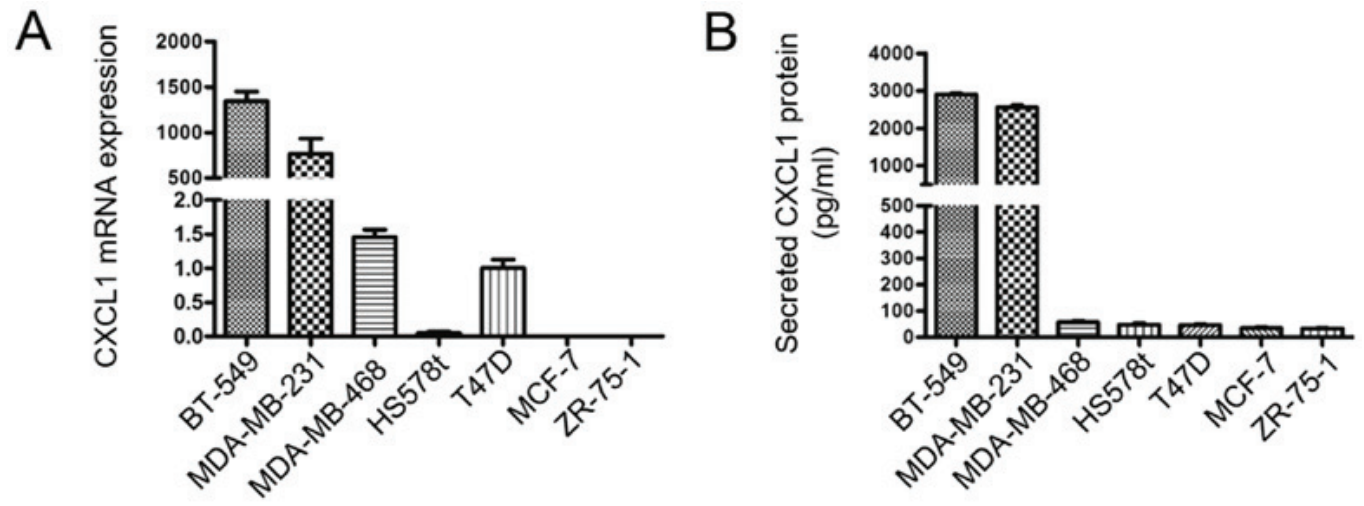

C

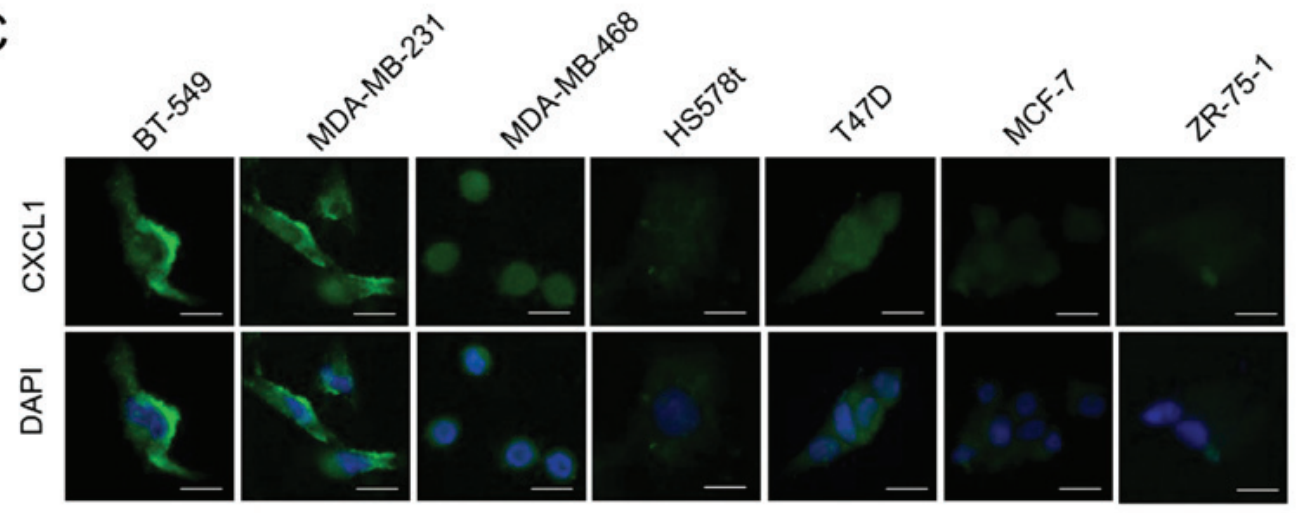

$\mathrm{D}$

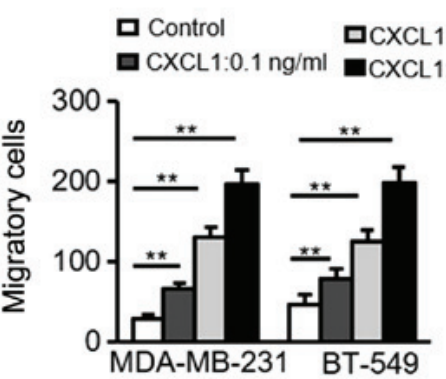

$\mathrm{F}$

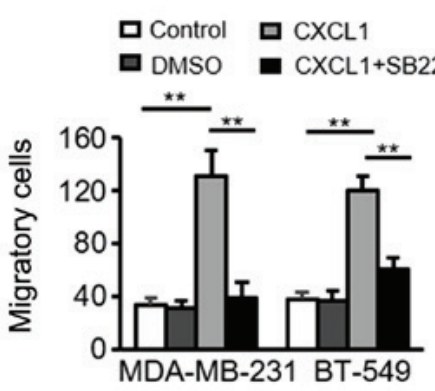

$\mathrm{E}$
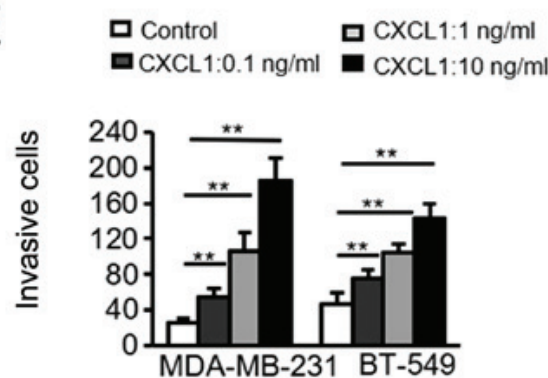

G

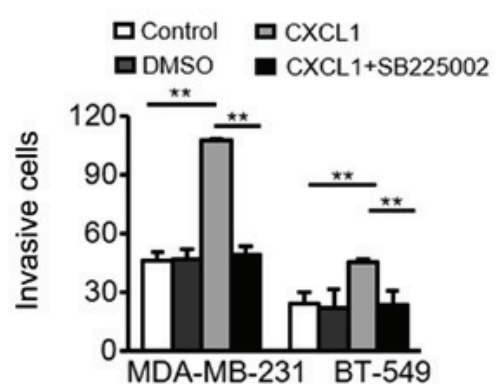

Figure 2. Upregulation of CXCL1 in ER-negative cancer cells, and the CXCL1/CXCR2-induced migration and invasion of ER-negative cancer cells. (A) Quantification of CXCL1 mRNA was performed via reverse transcription-quantitative PCR analysis in four ER-negative cell lines (BT-549, MDA-MB-231, MDA-MB-468, HS578t) and three ER-positive cell lines (T47D, MCF-7, ZR-75-1). Data are presented as the mean \pm standard deviation from three independent experiments. (B) Secreted CXCL1 protein in the supernatant from BC cells was collected and measured by ELISA. Data are presented as the mean \pm standard deviation from three independent experiments. (C) Expression and localization of CXCL1 in BC cells as determined by immunofluorescence staining. Scale bars, $100 \mu \mathrm{m}$. Magnification, x400. (D) Migratory and (E) invasive abilities of MDA-MB-231 and BT-549 cells incubated with/without rhCXCL1 (0.1, 1.0 and $10 \mathrm{ng} / \mathrm{ml}$ ) were evaluated by Transwell assays. Magnification, x200. ${ }^{* *} \mathrm{P}<0.001$. (F) Migration and (G) invasion of MDA-MB-231 and BT-549 cells were evaluated using Transwell assays following treatment with/without rhCXCL1 (10 ng/ml) or the CXCR2 antagonist SB225002 (200 nM). ${ }^{* *}<0.001 .8 C$, breast cancer; CXCL1, chemokine (C-X-C motif) ligand 1; ER, estrogen receptor; rh, recombinant human.

ER-positive BC cell lines (T47D, MCF-7, ZR-75-1) were analyzed. The mRNA and protein CXCL1 expression levels in these cells were detected by RT-qPCR and ELISA. The levels of CXCL1 mRNA (Fig. 2A) and protein (Fig. 2B) were markedly upregulated in the ER-negative BC cells compared with the ER-positive cells. CXCL1 was predominantly located in the cell cytoplasm, as determined via IF assays (Fig. 2C). These data demonstrated that CXCL1 exhibits increased expression in ER-negative BC cells compared with ER-positive BC cells. 
A

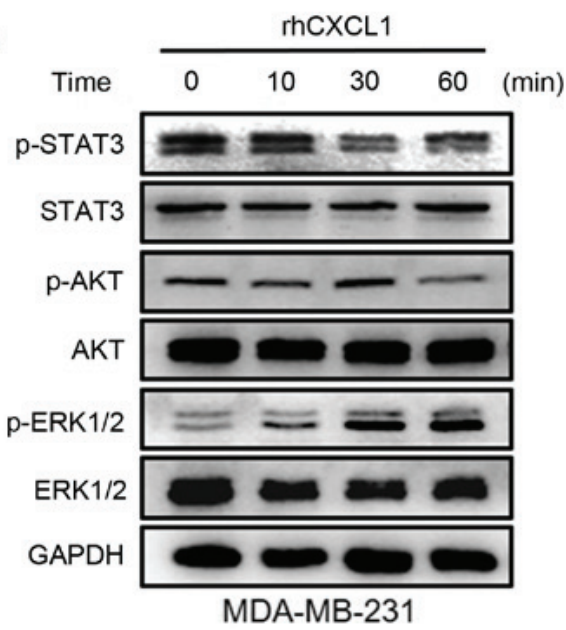

B

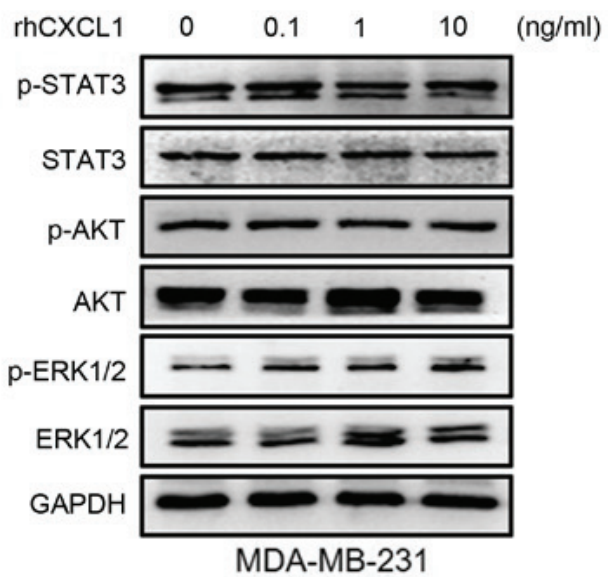

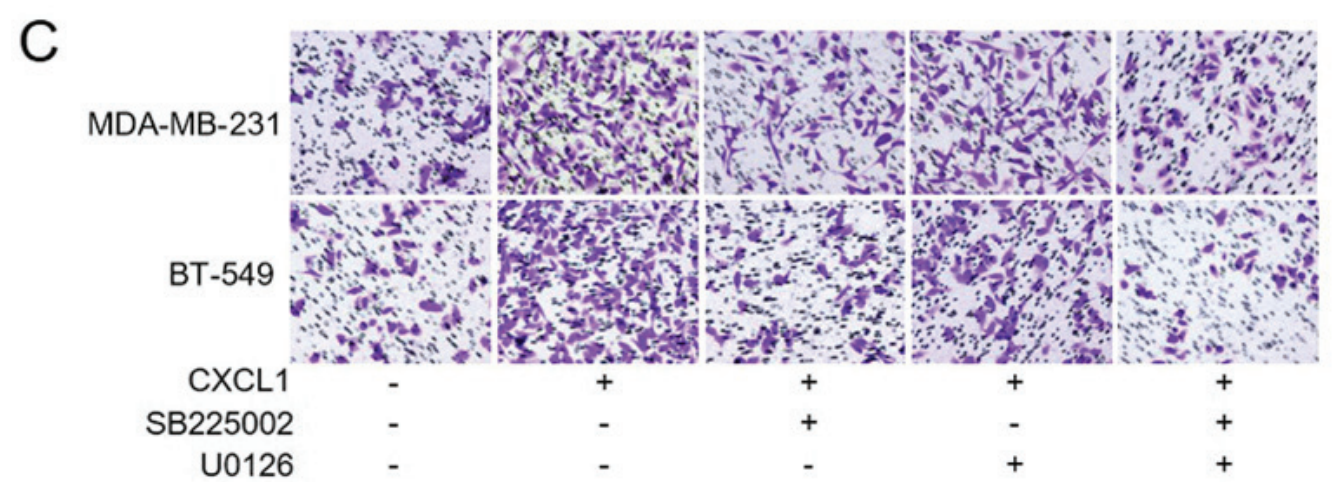
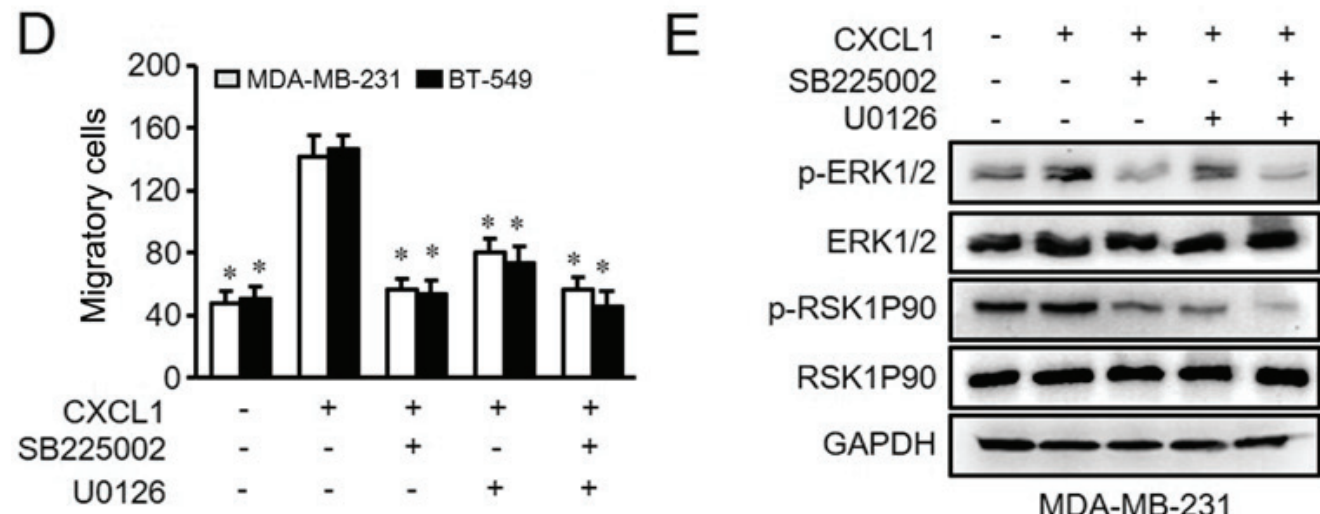

Figure 3. CXCL1/CXCR2 induces ER-negative breast cancer cell invasion and migration via the ERK1/2 pathway. (A and B) Activation of the MAPK/ERK, JNK/STAT3 and MAPK/AKT pathways in MDA-MB-231 cells stimulated with rhCXCL1 was measured. (C and D) Cell migration was measured for MDA-MB-231 and BT-459 cells. Cells were pretreated with/without SB225002 (200 nM) for $2 \mathrm{~h}$ or U0126 $(10 \mu \mathrm{M})$ for $1 \mathrm{~h}$ in combination with/without rhCXCL1 $(10 \mathrm{ng} / \mathrm{ml}) .{ }^{*} \mathrm{P}<0.05$ vs. CXCL1 only. (E) Western blot analysis to determine the protein and phosphorylation levels of ERK1/2 and RSK1P90 in MDA-MB-231 cells pretreated with/without SB225002 $(200 \mathrm{nM})$ or U0126 $(10 \mu \mathrm{M})$ in combination with/without rhCXCL1 $(10 \mathrm{ng} / \mathrm{ml})$. GAPDH was used as the loading control. CXCL1, chemokine (C-X-C motif) ligand 1; ER, estrogen receptor; p-, phosphorylated; rh, recombinant human; RSK1P90, ribosomal S6 kinase P90.

CXCL1 promotes ER-negative BC cell migration and invasion in a CXCR2-dependent manner. Based on the aforementioned findings, it was hypothesized that CXCL1 overexpression in ER-negative $\mathrm{BC}$ may be associated with the aggressive nature of ER-negative BC. To investigate the effect of CXCL1 on the invasion of ER-negative BCs, MDA-MB-231 and BT-549 cells were treated with/without rhCXCL1 (0.1, 1.0 and $10 \mathrm{ng} / \mathrm{ml})$. A Transwell assay revealed that CXCL1 significantly increased the migration (Fig. 2D) and invasion (Fig. 2E) of MDA-MB-231 and BT-549 cells in a dose-dependent manner, compared with control treatment. Subsequently, SB225002, a specific CXCR2 antagonist, was used to determine whether the effects of CXCL1 on the migration and invasion of ER-negative cells were associated with CXCR2. The CXCL1-induced increases in cell migration (Fig. 2F) and invasion (Fig. 2G) were significantly attenuated by treatment with SB225002. In summary, these data suggested that enhanced CXCL1 in ER-negative BC promotes cell migration and invasion in a CXCR2-dependent manner.

CXCL1/CXCR2 induces ER-negative BC cell invasion and migration via the ERK1/2 pathway. Previous studies have reported that chemokines can bind to their recep- 
A

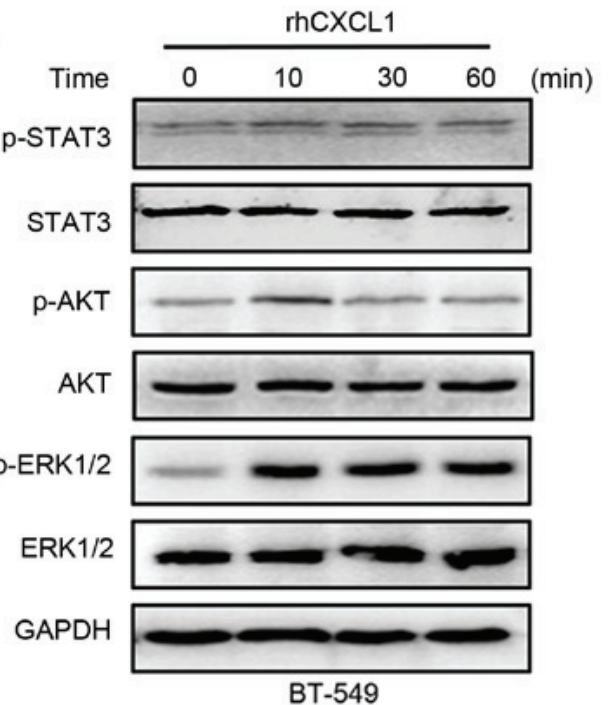

B

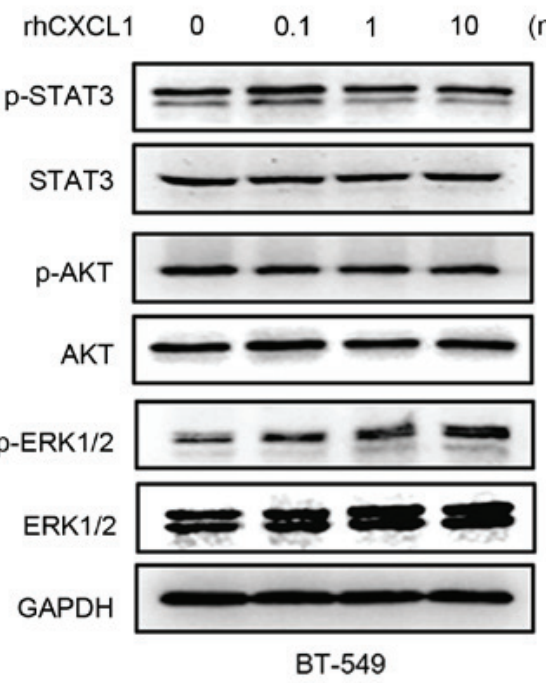

C

MDA-MB-231

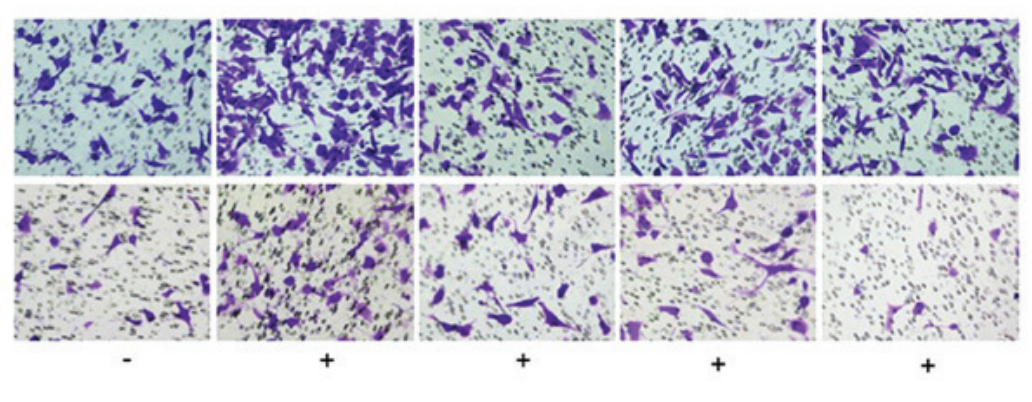

CXCL1

SB225002

U0126

D

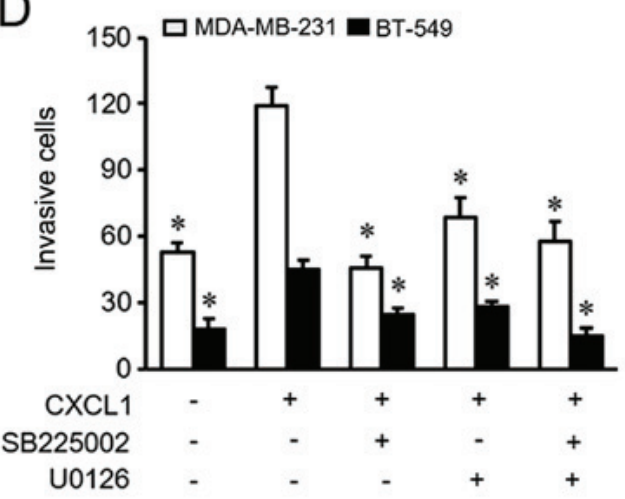

E

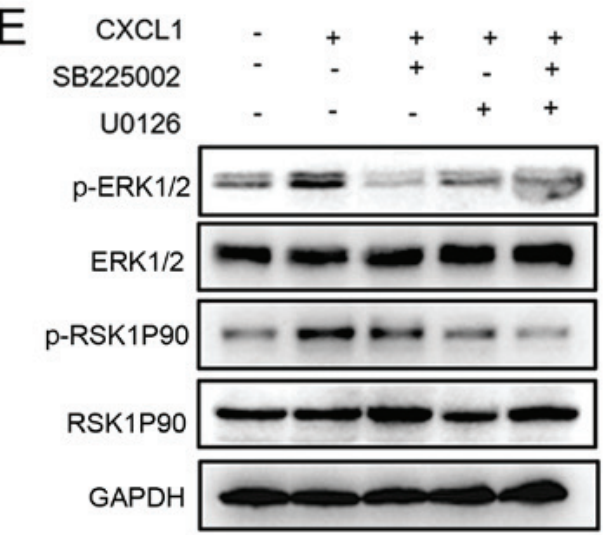

Figure 4. CXCL1/CXCR2 induces ER-negative breast cancer cell invasion and migration via the ERK1/2 pathway. (A and B) Activation of the MAPK/ERK, JNK/STAT3 and MAPK/AKT pathways in BT-549 cells stimulated with rhCXCL1 was measured. (C and D) Invasion assay of MDA-MB-231 and BT-549 cells pretreated with/without SB225002 $(200 \mathrm{nM})$ for $2 \mathrm{~h}$ or $\mathrm{U} 0126(10 \mu \mathrm{M})$ for $1 \mathrm{~h}$ were co-cultured with/without rhCXCL1 (10 ng/ml). *P<0.05 vs. CXCL1 only. (E) Western blot analysis of the ERK1/2/RSK1P90 signaling in BT-549 cells pretreated with/without SB225002 (200 nM) or U0126 (10 $\mu$ M) were stimulated with/without rhCXCL1 (10 ng/ml). GAPDH was used as the loading control. CXCL1, chemokine (C-X-C motif) ligand 1; ER, estrogen receptor; p-, phosphorylated; rh, recombinant human; RSK1P90, ribosomal S6 kinase P90.

tors to induce cancer progression by stimulating a series of downstream signaling pathways, including the PI3K/AKT, Janus kinase (JAK)/STAT3 and ERK1/2 pathways (26-29). Therefore, possible signaling mechanisms associated with the CXCL1/CXCR2-induced promotion of ER-negative BC cell migration and invasion were examined by western blot analysis. It was identified that only $\mathrm{p}$-ERK1/2 was activated by rhCXCL1 in MDA-MB-231 and BT-549 cells in a time- and dose-dependent manner (Figs. 3A and B, and 4A and B).
Next, the present study used inhibitors of CXCR2 and $M E K$ to treat MDA-MB-231ß and BT-549 cells. The results demonstrated that CXCL1-mediated cell migration and invasion were significantly inhibited by either SB225002 or U0126 compared with rhCXCL1 treatment alone (Figs. 3C and D, and 4C and D). Similarly, the activated ERK1/2 and RSK1P90 proteins in the ERK pathway that were stimulated by CXCL1 were inhibited following treatment with SB225002 and U0126 (Figs. 3E and 4E). These findings suggested that 
A

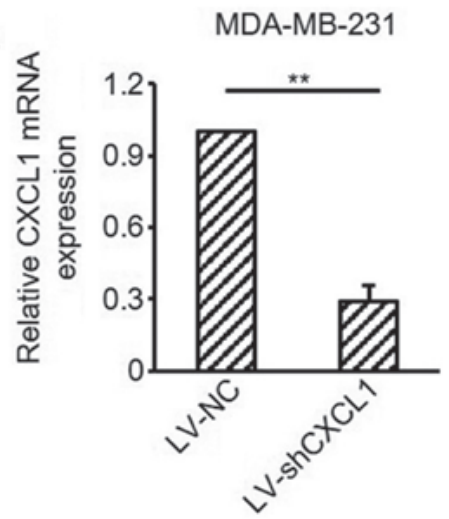

C

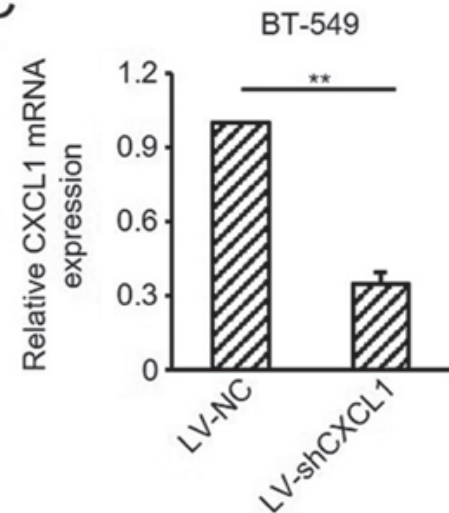

B

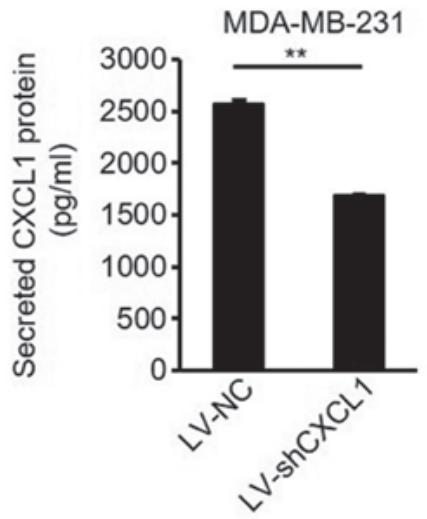

D

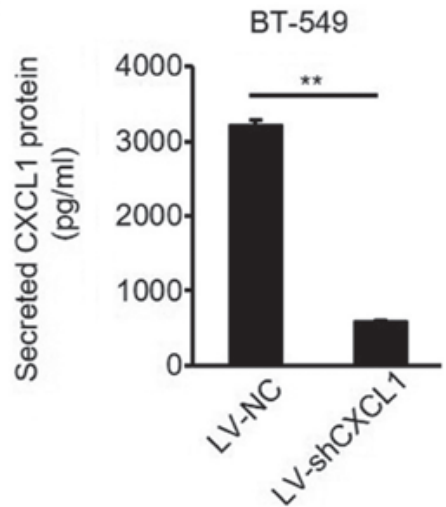

Figure 5. Interference efficiency of shCXCL1. Knockdown of CXCL1 in MDA-MB-231 and BT-549 ER-negative breast cancer cells was detected by (A and C) reverse transcription-quantitative PCR and (B and D) ELISA. ${ }^{* *} \mathrm{P}<0.001$. CXCL1, chemokine (C-X-C motif) ligand 1; ER, estrogen receptor; LV, lentivirus; NC, negative control; sh, short hairpin RNA.

CXCL1 regulates the migration and invasion of ER-negative cells via ERK signaling in a CXCR2-dependent manner.

Knockdown of CXCL1 reduces ER-negative BC cell migration and invasion via the ERK1/2 pathway. To further determine the role of CXCL1 in the invasion of ER-negative BC cells, the lentivirus-mediated shCXCL1 and control vector were stably transduced into ER-negative MDA-MB-231 and BT-549 cells. The efficiency of knockdown was verified via RT-qPCR analysis and ELISAs (Fig. 5A-D). As hypothesized, reduced CXCL1 significantly attenuated the migratory abilities of MDA-MB-231 and BT-549 cells (Fig. 6A and B). Similar results were observed in the cell invasion assay (Fig. 6C and D). Subsequently, the levels and phosphorylation of ERK and RSK1P90, key proteins associated with ERK signaling activation, were detected via western blot analysis. It was identified that knockdown of CXCL1 in MDA-MB-231 and BT-549 cells inhibited ERK1/2 pathway activation (Fig. 6E and F). These data demonstrated that silencing CXCL1 in ER-negative cells prevents cell migration and invasion due to inhibition of the ERK1/2 pathway.

Effects of CXCL1 stimulation on MMP2/9 expression by ERK1/2 activation. It has been reported that MMP2 and MMP9 are strongly associated with tumor metastasis (30-33). Thus, it was hypothesized that activated ERK1/2 signaling may contribute to CXCL1-mediated MMP2/9 expression in ER-negative cells. To verify this hypothesis, the MDA-MB-231 and BT-549 cells pretreated with SB225002, U0126 and/or
rhCXCL1 were evaluated for their mRNA and protein expression levels of MMP2/9 via RT-qPCR and western blot analyses. As presented in Fig. 7A and C, rhCXCL1 treatment significantly increased the mRNA and protein levels of MMP2/9; however, the effects of CXCL1 on the activation of MMP2/9 in MDA-MB-231 cells were reversed by pretreatment with SB225002 or U0126. Similar results were observed in BT-549 cells (Fig. 7B and D). Furthermore, it was determined that knockdown of CXCL1 in MDA-MB-231 and BT-549 cells by shCXCL1 inhibited ERK/MMP2/9 signaling, and this inhibitory effect could be reversed by the treatment of these cells with rhCXCL1 (Fig. 7E and F). In summary, these data suggested that CXCL1 can stimulate MMP2/9 expression in ER-negative cells via ERK1/2 activation in a CXCR2-dependent manner.

CXCL1 protein is highly expressed in ER-negative BC tissues and positively associated with p-ERK1/2 in BC tissues. The protein expression levels of CXCL1 and p-ERK1/2 were detected in $88 \mathrm{BC}$ tissue samples via IHC. CXCL1 and p-ERK1/2 were expressed in $62.5 \%(55 / 88)$ and $52.3 \%(46 / 88)$ of these tumor cases, respectively. Representative images are presented in Fig. 8A, and quantitative analysis revealed that CXCL1 expression was significantly increased in ER-negative $\mathrm{BC}$ tissues compared with ER-positive tissues ( $\mathrm{P}<0.05$; Fig. 8B). Furthermore, a significant association between CXCL1 and p-ERK1/2 expression was observed via IHC; p-ERK1/2 expression was observed in $61.8 \%$ (34.55) of CXCL1-positive tissues, but only $36.4 \%$ (12/33) of CXCL1-negative tissues $(\mathrm{P}<0.05$; Fig. 8C). These data suggested an enhanced CXCL1 

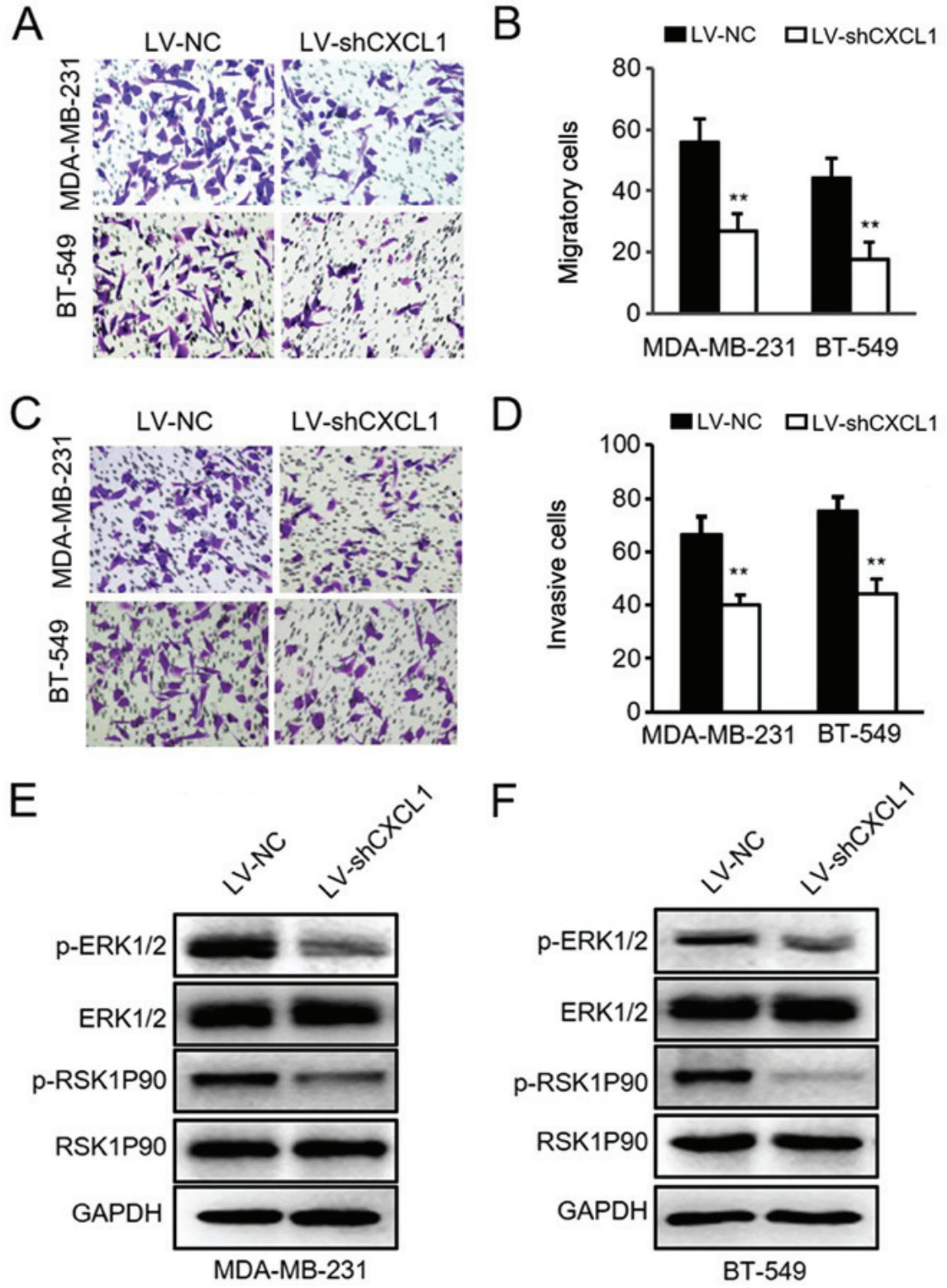

Figure 6. CXCL1-knockdown reduces ER-negative BC cell migration and invasion via the ERK1/2 pathway. (A and B) Cell migration was measured by Transwell assays for MDA-MB-231 and BT-549 cells transfected LV-NC or LV-shCXCL1. (C and D) Cell invasion was evaluated by Transwell assays for ER-negative BC cells transfected with LV-NC or LV-shCXCL1. (E and F) Proteins associated with the ERK1/2 pathway were analyzed via western blot analysis in CXCL1-silenced MDA-MB-231 and BT-549 cells. GAPDH was used as the loading control. ${ }^{* *} \mathrm{P}<0.001$ vs. LV-NC. BC, breast cancer; CXCL1, chemokine (C-X-C motif) ligand 1; ER, estrogen receptor; LV, lentivirus; NC, negative control; p-, phosphorylated; RSK1P90, ribosomal S6 kinase P90; sh, short hairpin RNA.

protein expression in ER-negative $\mathrm{BC}$, that is associated with the expression of $\mathrm{p}-\mathrm{ERK} 1 / 2$ protein.

\section{Discussion}

Chemokine systems, including chemokines and their receptors, serve important roles in cancer biology by inducing tumor cell growth, migration, invasion, chemoresistance and angiogenesis $(11,34)$. Chemokines can interact with cancer cells via two pathways; the autocrine pathway and the paracrine pathway (35). There is extensive evidence that CXCL1 is produced by immune cells and stromal cells, and acts in a paracrine manner in the tumor microenvironment during carcinogenesis $(14,36)$. However, tumor-derived CXCL1 has rarely been reported to promote cell metastasis in an autocrine manner in human BC. In the present study, CXCL1 mRNA levels and CXCL1 secretion levels in the supernatant were determined to be upregulated in ER-negative cells. Similar results have been previously reported for another chemokine, IL-8 (37). The present study further revealed that CXCL1 could increase the metastatic potential of MDA-MB-231 and BT-549 cells in a dose-dependent manner in vitro. These results indicated that tumor-derived CXCL1 may be associated with the invasive ability of ER-negative BC cells.

Certain studies have suggested that patients with pancreatic, gastric or hepatocellular cancer exhibit increased levels of CXCL1 in cancer tissues (38-40). By contrast, other studies have demonstrated that CXCL1 mRNA expression levels in hepatic tumors were similar between cancerous and non-cancerous tissues (41). Notably, in the present study, no difference in the mRNA expression level of CXCL1 was identified between the adjacent non-tumor and tumor tissues 
A

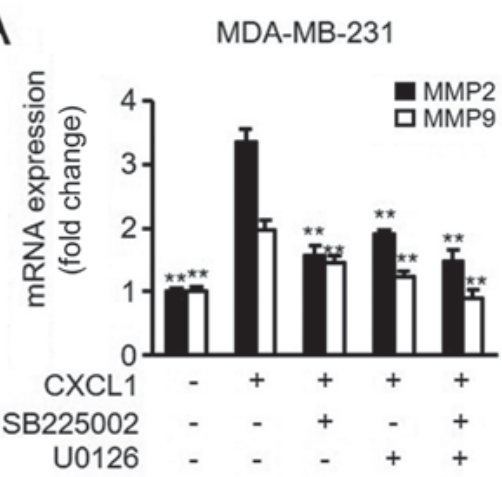

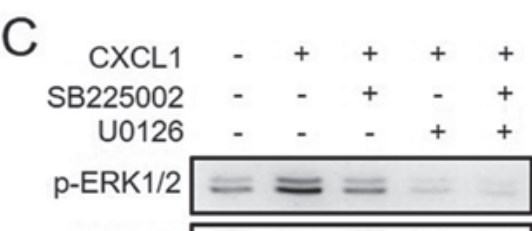
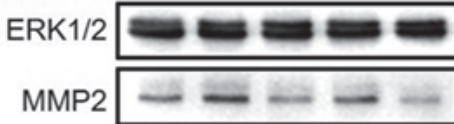

MMP9 $-\cdots+\cdots$

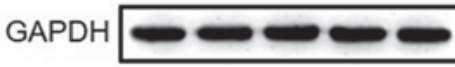

MDA-MB-231

E

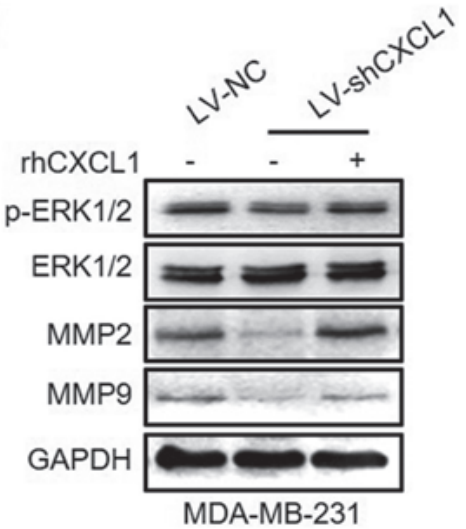

B BT-549

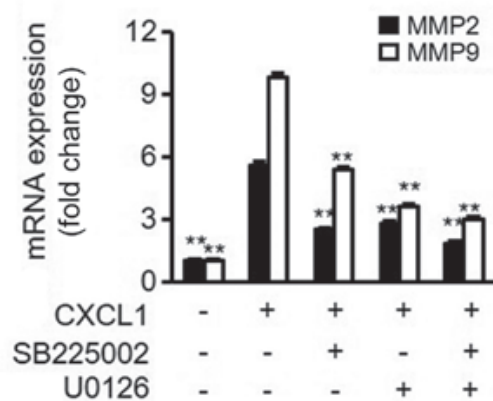

D

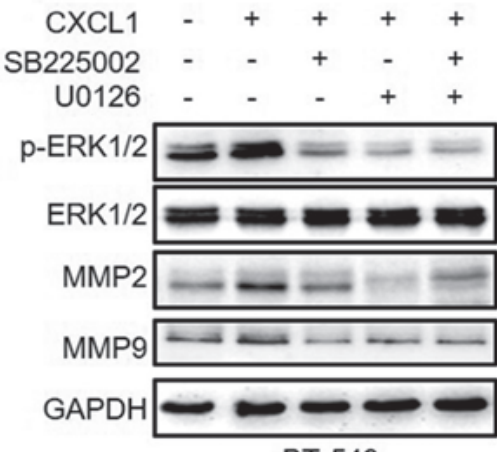

F

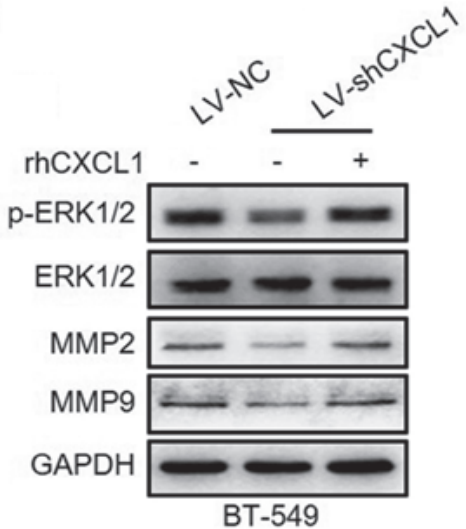

Figure 7. Effects of CXCL1-induced ERK1/2 activation on MMP2/9 expression. ER-negative breast cancer cells were incubated with/without SB225002 for $2 \mathrm{~h}$ and U0126 for $1 \mathrm{~h}$ prior to CXCL1 treatment. (A and B) Expression levels of MMP2/9 mRNA were determined via reverse transcription-quantitative PCR analysis. ${ }^{* *} \mathrm{P}<0.001$ vs. rhCXCL1 treatment alone. (C and D) Protein expression levels of MMP2/9 were measured via western blot analysis. (E and F) Activation of ERK and MMP2/9 in MDA-MB-231 or BT-549 cells transfected with shCXCL1 and incubated with rhCXCL1 was detected. CXCL1, chemokine (C-X-C motif) ligand 1; ERK1/2, extracellular signal-regulated kinase 1/2; LV, lentivirus; MMP, matrix metalloproteinase; NC, negative control; p-, phosphorylated; rh, recombinant human; sh, short hairpin RNA.

for all patients with BC (data not shown). However, it was revealed that CXCL1 mRNA was upregulated in patients with ER-negative BC compared with ER-positive BC. In addition, a marked difference was observed in the CXCL1 protein levels between ER-negative and ER-positive BC tumor tissues via IHC staining. These findings indicated that CXCL1 may be a biomarker for ER-negative BC.

Chemokines can bind to specific G-protein coupled receptors to activate multiple downstream signaling pathways in cancer. In addition to JAK/STAT3 and PI3K/AKT signaling, the MAPK/ERK signaling pathway is one of these targeted pathways (42-45). However, in the present study, it was identified that only ERK signaling was stimulated by rhCXCL1 in ER-negative cells in a dose- and time-dependent manner; knockdown of CXCL1 in MDA-MB-231 and BT-549 cells inhibited the activation of the ERK pathway. Furthermore, the present results demonstrated that CXCL1-mediated ER-negative BC cell migration and invasion could be significantly suppressed following inhibition of the ERK1/2 pathway using U0126. ERK1/2 phosphorylation stimulated by CXCL1 has been reported in other types of cell, including endothelial cells, muscle cells and astrocytes (46-48). Furthermore, cellular migration and invasion stimulated by the MAPK pathway has been well reported (45). However, to the best of our knowledge, no previous study has reported that the ERK pathway may serve a key role in the CXCL1-induced metastasis of ER-negative BC.

Activation of the ERK/MMP2/9 pathway axis regulated by CXCL1 may serve a crucial role in ER-negative cell metastasis. MMP2 and MMP9, members of the MMP family, 


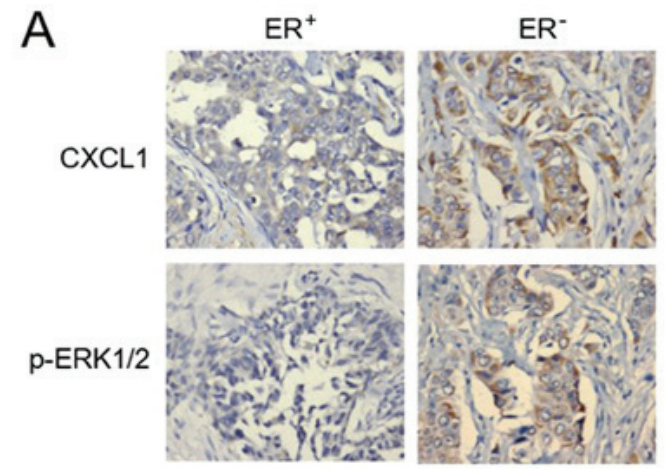

B

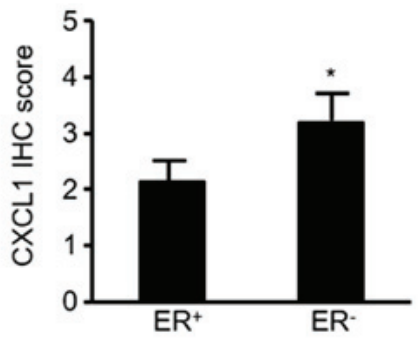

C

Breast cancer specimens $(n=88)$

\begin{tabular}{|cccc|}
\hline \multirow{2}{*}{ CXCL1 expression } & \multicolumn{2}{c|}{ p-ERK1/2 expression } & P-value \\
\cline { 2 - 3 } & Positive (46) & Negative (42) & $<0.05$ \\
\hline Positive (55) & $34(61.8 \%)$ & $21(38.2 \%)$ & \\
\hline Negative (33) & $12(36.4 \%)$ & $21(63.6 \%)$ & \\
\hline
\end{tabular}

D

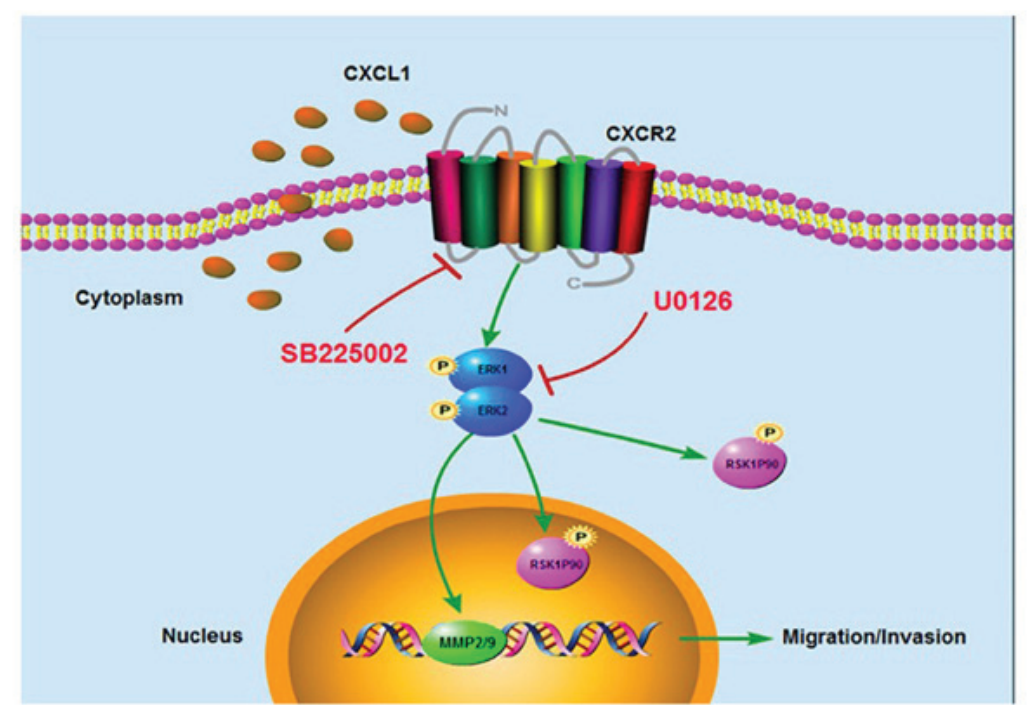

Figure 8. p-ERK1/2 is positively associated with CXCL1 in BC samples. (A) Representative images of CXCL1 and p-ERK1/2 IHC staining in ER-negative and ER-positive BC tissues. (B) Quantification of CXCL1 levels in ER-negative and ER-positive BC samples was achieved by pathological scoring. ${ }^{*} \mathrm{P}<0.05$ vs. ER-positive BC tissues. (C) Summary of CXCL1 and p-ERK1/2 expression levels in all BC tissues determined by IHC staining. (D) Schematic diagram presents a potential model of how CXCL1 promotes cell migration and invasion via the ERK/MMP2/9 pathway in ER-negative BC. BC, breast cancer; CXCL1, chemokine (C-X-C motif) ligand 1; ER, estrogen receptor; ERK1/2, extracellular signal-regulated kinase 1/2; IHC, immunohistochemistry; MMP, matrix metalloproteinase; p-, phosphorylated; RSK1P90, ribosomal S6 kinase P90.

have been reported to drive metastasis in various cancer types, including pancreatic, hepatocellular and lung cancers (49). The upregulation of MMP2 and MMP9 is associated with poor prognosis in patients with ovarian and breast cancers $(50,51)$. Furthermore, it has been reported that MMP2 and MMP9 promote the migration and invasion of cancer cells via regulation of the ERK signaling pathway $(52,53)$. The present study demonstrated that CXCL1 could upregulate the expression of MMP2/9 in ER-negative cells, which could be reversed by treatment with the ERK inhibitor U0126. Additionally, knockdown of CXCL1 in ER-negative cells downregulated MMP2/9 expression, and this effect was significantly reversed by addition of rhCXCL1. Although MMP2/9 upregulation induced by CXCL1 derived from lymphatic endothelial cells has previously been reported in gastric cancer (14), this study did not report that the CXCL1-induced upregulation of
MMP2/9 expression is dependent on ERK1/2 signaling, as was indicated in the present study for ER-negative BC.

In summary, the present findings revealed that the expression levels of CXCL1 were upregulated in ER-negative BC. It was demonstrated that CXCL1 can stimulate tumor cell invasion via the ERK1/2/MMP2/9 pathway axis. Therefore, CXCL1 may serve as a potential therapeutic target in ER-negative BC.

\section{Acknowledgements}

Not applicable.

\section{Funding}

This work was supported in part by National Natural Science Foundation of China (grant nos. NSFC 81472658 and NSFC 
81772979) and Chongqing Natural Science Foundation (grant no. cstc2015shmszx0269) for Shengchun Liu; and partly supported by National Natural Science Foundation of China (grant nos. NSFC 81472476 and NSFC 31671481) for Manran Liu.

\section{Availability of data and materials}

The datasets used during the present study are available from the corresponding author upon reasonable request.

\section{Authors' contributions}

SL, ML, CY and HY designed the study. CY and HY performed the majority of the experiments and were major contributors in writing the manuscript. XL, LJ and KT participated in the collection of clinical samples and prepared experimental materials. RC and MP conducted the statistical analysis of clinical data and analyzed a substantial quantity of experimental data. All authors have read and approved the final submitted manuscript.

\section{Ethics approval and consent to participate}

The study was approved by the Ethics committee of Chongqing Medical University. Written informed consent was obtained from all patients.

\section{Patient consent to participate}

Not applicable.

\section{Competing interests}

The authors declare that they have no competing interests.

\section{References}

1. Polyak K: Heterogeneity in breast cancer. J Clin Invest 121 3786-3788, 2011

2. Carey LA, Perou CM, Livasy CA, Dressler LG, Cowan D, Conway K, Karaca G, Troester MA, Tse CK, Edmiston S, et al: Race, breast cancer subtypes, and survival in the Carolina Breast Cancer Study. JAMA 295: 2492-2502, 2006.

3. Litzenburger BC and Brown PH: Advances in Preventive Therapy for Estrogen-Receptor-Negative Breast Cancer. Curr Breast Cancer Rep 6: 96-109, 2014.

4. Barcellos-Hoff MH: Does microenvironment contribute to the etiology of estrogen receptor-negative breast cancer? Clin Cancer Res 19: 541-548, 2013.

5. Chen JQ and Russo J: ERalpha-negative and triple negative breast cancer: Molecular features and potential therapeutic approaches. Biochim Biophys Acta 1796: 162-175, 2009.

6. Shen K, Rice SD, Gingrich DA, Wang D, Mi Z, Tian C, Ding Z, Brower SL, Ervin PR Jr, Gabrin MJ, et al: Distinct genes related to drug response identified in ER positive and ER negative breast cancer cell lines. PLoS One 7: e40900, 2012.

7. Bianchini G, Qi Y, Alvarez RH, Iwamoto T, Coutant C, Ibrahim NK, Valero V, Cristofanilli M, Green MC, Radvanyi L, et al: Molecular anatomy of breast cancer stroma and its prognostic value in estrogen receptor-positive and -negative cancers. J Clin Oncol 28: 4316-4323, 2010.

8. Milne RL, Kuchenbaecker KB, Michailidou K, Beesley J, Kar S, Lindström S, Hui S, Lemaçon A, Soucy P, Dennis J, et al; ABCTB Investigators; EMBRACE; GEMO Study Collaborators; HEBON; kConFab/AOCS Investigators; NBSC Collaborators: Identification of ten variants associated with risk of estrogen-receptor-negative breast cancer. Nat Genet 49: 1767-1778, 2017.
9. Silva RL, Lopes AH, Guimarães RM and Cunha TM: CXCL1/CXCR2 signaling in pathological pain: Role in peripheral and central sensitization. Neurobiol Dis 105: 109-116, 2017.

10. Wang D, Yang W, Du J, Devalaraja MN, Liang P, Matsumoto K, Tsubakimoto K, Endo T and Richmond A: MGSA/GRO-mediated melanocyte transformation involves induction of Ras expression. Oncogene 19: 4647-4659, 2000.

11. Balkwill FR: The chemokine system and cancer. J Pathol 226: 148-157, 2012.

12. Acharyya S, Oskarsson T, Vanharanta S, Malladi S, Kim J,Morris PG Manova-Todorova K, Leversha M, Hogg N, Seshan VE, et al: A CXCL1 paracrine network links cancer chemoresistance and metastasis. Cell 150: 165-178, 2012.

13. Miyake M, Hori S, Morizawa Y, Tatsumi Y, Nakai Y, Anai S Torimoto K, Aoki K, TanakaN,Shimada K, etal:CXCL1-mediated interaction of cancer cells with tumor-associated macrophages and cancer-associated fibroblasts promotes tumor progression in human bladder cancer. Neoplasia 18: 636-646, 2016.

14. Xu J, Zhang C, He Y, Wu H, Wang Z, Song W, Li W, He W, Cai S and Zhan W: Lymphatic endothelial cell-secreted CXCL1 stimulates lymphangiogenesis and metastasis of gastric cancer. Int J Cancer 130: 787-797, 2012.

15. Wang Z, Wang Z, Li G, Wu H, Sun K, Chen J, Feng Y, Chen C, Cai S, Xu J, et al: CXCL1 from tumor-associated lymphatic endothelial cells drives gastric cancer cell into lymphatic system via activating integrin $\beta 1 / F A K / A K T$ signaling. Cancer Lett 385: 28-38, 2017.

16. Kuo PL, Shen KH,Hung SH and Hsu YL: CXCL1/GRO $\alpha$ increases cell migration and invasion of prostate cancer by decreasing fibulin-1 expression through NF- $\mathrm{KB} / \mathrm{HDAC} 1$ epigenetic regulation. Carcinogenesis 33: 2477-2487, 2012.

17. Han KQ, He XQ, Ma MY, Guo XD, Zhang XM, Chen J, Han H, Zhang WW,Zhu QG and Zhao WZ: Targeted silencing of CXCL1 by siRNA inhibits tumor growth and apoptosis in hepatocellular carcinoma. Int J Oncol 47: 2131-2140, 2015

18. Wang L, Zhang C, Xu J, Wu H, Peng J, Cai S and He Y: CXCL1 gene silencing inhibits HGC803 cell migration and invasion and acts as an independent prognostic factor for poor survival in gastric cancer. Mol Med Rep 14: 4673-4679, 2016.

19. Divella R, Daniele A, Savino E, Palma F, Bellizzi A, Giotta F, Simone G, Lioce M, Quaranta M, Paradiso A, et al: Circulating levels of transforming growth factor- $\beta$ eta (TGF- $\beta$ ) and chemokine (C-X-C motif) ligand-1 (CXCL1) as predictors of distant seeding of circulating tumor cells in patients with metastatic breast cancer. Anticancer Res 33: 1491-1497, 2013

20. Zou A, Lambert D, Yeh H, Yasukawa K, Behbod F, Fan F and Cheng N: Elevated CXCL1 expression in breast cancer stroma predicts poor prognosis and is inversely associated with expression of TGF- $\beta$ signaling proteins. BMC Cancer 14: 781, 2014.

21. Wang L, Hou Y, Sun Y, Zhao L, Tang X, Hu P, Yang J, Zeng Z, Yang G, Cui X, et al: c-Ski activates cancer-associated fibroblasts to regulate breast cancer cell invasion. Mol Oncol 7: 1116-1128, 2013.

22. Livak KJ and Schmittgen TD: Analysis of relative gene expression data using real-time quantitative PCR and the $2(-\Delta \Delta \mathrm{C}(\mathrm{T})$ method. Methods 25: 402-408, 2001.

23. Rhodes DR, Yu J, Shanker K, Deshpande N, Varambally R, Ghosh D, Barrette T, Pandey A and Chinnaiyan AM: ONCOMINE: A cancer microarray database and integrated data-mining platform. Neoplasia 6: 1-6, 2004.

24. Sorlie T, Tibshirani R, Parker J, Hastie T, Marron JS, Nobel A, Deng S, Johnesn H, Pesich R, Geisler S, et al: Repeated observation of breast tumor subtypes in independent gene expression data sets. Proc Natl Acad Sci USA 100: 8418-8423, 2003.

25. Desmedt C, Piette F, Loi S, Wang Y, Lallemand F, Haibe-Kains B, Viale G, Delorenzi M, ZhangY, d'Assignies MS, et al: Strong time dependence of the 76-gene prognostic signature for node-negative breast cancer patients in the TRANSBIG multicenter independent validation series. Clin Cancer Res 13: 3207-3214, 2007.

26. Zhao J, Ou B, Han D, Wang P, Zong Y, Zhu C, Liu D, Zheng M, Sun J, Feng H, et al: Tumor-derived CXCL5 promotes human colorectal cancer metastasis through activation of the ERK/Elk-1/Snail and AKT/GSK3 $\beta / \beta$-catenin pathways. Mol Cancer 16: 70, 2017.

27. Fu XT, Dai Z, Song K, Zhang ZJ, Zhou ZJ, Zhou SL, Zhao YM, Xiao YS, Sun QM, Ding ZB, et al: Macrophage-secreted IL-8 induces epithelial-mesenchymal transition in hepatocellular carcinoma cells by activating the JAK2/STAT3/Snail pathway. Int J Oncol 46: 587-596, 2015. 
28. Li S, Lu J, Chen Y, Xiong N, Li L, Zhang J, Yang H, Wu C, Zeng $\mathrm{H}$ and Liu Y: MCP-1-induced ERK/GSK-3 $\beta /$ Snail signaling facilitates the epithelial-mesenchymal transition and promotes the migration of MCF-7 human breast carcinoma cells. Cell Mol Immunol 14: 621-630, 2017.

29. Ou B, Zhao J, Guan S, Feng H, Wangpu X, Zhu C, Zong Y, Ma J, Sun J, Shen X, et al: CCR4 promotes metastasis via ERK/NF- $\kappa \mathrm{B} / \mathrm{MMP} 13$ pathway and acts downstream of TNF- $\alpha$ in colorectal cancer. Oncotarget 7: 47637-47649, 2016.

30. Jabłońska-Trypuć A, Matejczyk M and Rosochacki S: Matrix metalloproteinases (MMPs), the main extracellular matrix (ECM) enzymes in collagen degradation, as a target for anticancer drugs J Enzyme Inhib Med Chem 31 (Suppl 1): 177-183, 2016.

31. Nishio K, Motozawa K, Omagari D, Gojoubori T, Ikeda T, Asano $\mathrm{M}$ and Gionhaku N: Comparison of MMP2 and MMP9 expression levels between primary and metastatic regions of oral squamous cell carcinoma. J Oral Sci 58: 59-65, 2016.

32. Zheng Y, Miu Y, Yang X, Yang X and Zhu M: CCR7 mediates TGF- $\beta 1$-induced human malignant glioma invasion, migration, and epithelial-mesenchymal transition by activating MMP2/9 through the nuclear factor kappaB signaling pathway. DNA Cell Biol 36: 853-861, 2017.

33. Chen SX, Yin JF, Lin BC, Su HF, Zheng Z, Xie CY and Fei ZH: Upregulated expression of long noncoding RNA SNHG15 promotes cell proliferation and invasion through regulates MMP2/ MMP9 in patients with GC. Tumour Biol 37: 6801-6812, 2016.

34. Balkwill F: Cancer and the chemokine network. Nat Rev Cancer 4: 540-550, 2004.

35. Mantovani A, Savino B, Locati M, Zammataro L, Allavena P and Bonecchi R: The chemokine system in cancer biology and therapy. Cytokine Growth Factor Rev 21: 27-39, 2010.

36. Zhang T, Tseng C, Zhang Y, Sirin O, Corn PG, Li-Ning-Tapia EM, Troncoso P, Davis J, Pettaway C, Ward J, et al: CXCL1 mediates obesity-associated adipose stromal cell trafficking and function in the tumour microenvironment. Nat Commun 7: 11674, 2016

37. Freund A, Chauveau C, Brouillet JP, Lucas A, Lacroix M, Licznar A, Vignon F and Lazennec G: IL-8 expression and its possible relationship with estrogen-receptor-negative status of breast cancer cells. Oncogene 22: 256-265, 2003

38. Lian S, Zhai X, Wang X, Zhu H, Zhang S, Wang W, Wang Z and Huang J: Elevated expression of growth-regulated oncogene-alpha in tumor and stromal cells predicts unfavorable prognosis in pancreatic cancer. Medicine (Baltimore) 95: e4328, 2016.

39. Han KQ, Han H, He XQ, Wang L, Guo XD, Zhang XM, Chen J, Zhu QG, Nian H, Zhai XF, et al: Chemokine CXCL1 may serve as a potential molecular target for hepatocellular carcinoma. Cancer Med 5: 2861-2871, 2016.

40. Xiang Z, Jiang DP, Xia GG, Wei ZW, Chen W, He Y and Zhang CH: CXCL1 expression is correlated with Snail expression and affects the prognosis of patients with gastric cancer. Oncol Lett 10: 2458-2464, 2015

41. Cui X, Li Z, Gao J, Gao PJ, Ni YB and Zhu JY: Elevated CXCL1 increases hepatocellular carcinoma aggressiveness and is inhibited by miRNA-200a. Oncotarget 7: 65052-65066, 2016.
42. Zhou J, Yi L, Ouyang Q, Xu L, Cui H and Xu M: Neurotensin signaling regulates stem-like traits of glioblastoma stem cells through activation of IL-8/CXCR1/STAT3 pathway. Cell Signal 26: 2896-2902, 2014

43. Zhou B, Sun C, Li N, Shan W, Lu H, Guo L, Guo E, Xia M, Weng D, Meng L, et al: Cisplatin-induced CCL5 secretion from CAFs promotes cisplatin-resistance in ovarian cancer via regulation of the STAT3 and PI3K/Akt signaling pathways. Int J Oncol 48: 2087-2097, 2016.

44. Lin HY, Sun SM, Lu XF, Chen PY, Chen CF, Liang WQ and Peng CY: CCR10 activation stimulates the invasion and migration of breast cancer cells through the ERK1/2/MMP-7 signaling pathway. Int Immunopharmacol 51: 124-130, 2017.

45. Xiong Y, Huang F, Li X, Chen Z, Feng D, Jiang H, Chen W and Zhang X: CCL21/CCR7 interaction promotes cellular migration and invasion via modulation of the MEK/ERK1/2 signaling pathway and correlates with lymphatic metastatic spread and poor prognosis in urinary bladder cancer. Int J Oncol 51: 75-90, 2017.

46. Miyake M, Goodison S, Urquidi V, Gomes Giacoia E and Rosser CJ: Expression of CXCL1 in human endothelial cells induces angiogenesis through the CXCR2 receptor and the ERK1/2 and EGF pathways. Lab Invest 93: 768-778, 2013.

47. Al-Alwan LA, Chang Y, Rousseau S, Martin JG, Eidelman DH and Hamid Q: CXCL1 inhibits airway smooth muscle cell migration through the decoy receptor Duffy antigen receptor for chemokines. J Immunol 193: 1416-1426, 2014.

48. Filipovic R and Zecevic N: The effect of CXCL1 on human fetal oligodendrocyte progenitor cells. Glia 56: 1-15, 2008.

49. Alaseem A, Alhazzani K, Dondapati P, Alobid S, Bishayee A and Rathinavelu A: Matrix Metalloproteinases: A challenging paradigm of cancer management. Semin Cancer Biol 56: 100-115, 2019.

50. Zeng L, Qian J, Zhu F, Wu F, Zhao H and Zhu H: The prognostic values of matrix metalloproteinases in ovarian cancer. J Int Med Res: May 17,2019 (Epub ahead of print). doi: 10.1177/0300060519825983.

51. Ren F, Tang R, Zhang X, Madushi WM, Luo D, Dang Y, Li Z, Wei K and Chen G: Overexpression of MMP family members functions as prognostic biomarker for breast cancer patients: A systematic review and meta-snalysis. PLoS One 10: e0135544, 2015.

52. Bai L, Lin G, Sun L, Liu Y, Huang X, Cao C, Guo Y and Xie C: Upregulation of SIRT6 predicts poor prognosis and promotes metastasis of non-small cell lung cancer via the ERK1/2/MMP9 pathway. Oncotarget 7: 40377-40386, 2016.

53. Wang Y, Wu N, Pang B, Tong D, Sun D, Sun H, Zhang C, Sun W, Meng X, Bai J, et al: TRIB1 promotes colorectal cancer cell migration and invasion through activation MMP-2 via FAK/Src and ERK pathways. Oncotarget 8: 47931-47942, 2017.

54. Robbins P, Pinder S, de Klerk N, Dawkins H, Harvey J, Sterrett G, Ellis I and Elston C: Histological grading of breast carcinomas: A study of interobserver agreement. Hum Pathol 26: 873-879, 1995.

This work is licensed under a Creative Commons Attribution-NonCommercial-NoDerivatives 4.0 International (CC BY-NC-ND 4.0) License. 